\title{
Early primary- rather than primordial follicles constitute the main follicular reserve in the African elephant (Loxodonta africana)
}

Fiona J. Stansfield ${ }^{*}{ }^{1}$ Helen M Picton ${ }^{2}$ and J. O. Nöthling ${ }^{1}$

${ }^{1}$ Department of Production Animal Studies, Faculty of Veterinary Science, University of Pretoria, Republic of South Africa.

${ }^{2}$ Division of Reproduction and Early Development, Leeds Institute of Genetics Health and Therapeutics, Faculty of Medicine and Health, University of Leeds, Leeds, UK LS2 9JT

*e-mail address fjs@zol.co.zw

Phone 2634861848

\section{Keywords}

Ovary, primordial follicle, elephant, corpus luteum, ovarian reserve 


\begin{abstract}
Information on the ovarian follicle reserve in the African elephant (Loxodonta africana) is lacking. This study set out to determine the ratios of early preantral follicles and their relative dimensions in the ovaries of 16 African elephant aged 10 to 34 years. The ovaries were sectioned histologically. Follicles were counted and classified according to expansion of the pre-granulosa cells. Early primary follicles were the most common $(75.8 \% \pm 11.8 \%)$, followed by true primary follicles $(23.8 \% \pm 11.8 \%)$, whereas primordial follicles were the most rare $(<2 \%)$. Measurements made on at least 100 early preantral follicles from each animal $(n=1464)$ indicate that growth in oocyte and nuclear diameters started with transition to the true primary stage $P<0.01$. This, together with the observed ratios between the three types of early preantral follicles suggest that both classical primordial and early primary follicles contribute to the ovarian reserve in the African elephant.
\end{abstract}

\title{
Introduction
}

For the management of the African elephant (Loxodonta africana), methods of contraception as well as assisted breeding are required (Brown et al., 2004; Delsink, 2006). The duration of the female elephants reproductive life is about 50 years (Perry, 1953; Freeman et al., 2009). Along with humans and whales they have the longest reproductive lifespan of mammals, requiring individual oocytes to remain meiotically competent for over 40 years (te Velde and Pearson, 2002) which exposes them to prolonged arrested development and structural damage (Faddy and Gosden, 1995). 
The last culling of wild elephant took place in Kruger National Park in South Africa in 1995 (Whyte, 2004). Since then there has been limited reproductive physiological research carried out on wild elephant, although endocrinological, ultrasound and behavioural studies have continued in captive elephant. Despite well-meaning efforts and investment, these animals are kept in unnatural environmental and social conditions and are showing worrying levels of acyclicity, particularly in older animals. In North American zoos the level of acyclicity/irregular cyclicity increased significantly between surveys in 2002 and 2005 (Proctor et al., 2010). It therefore becomes important to obtain biological samples from wild elephant populations and study their natural reproductive cycle when the opportunities arise.

Mammalian maternal ageing is accompanied by reduced oocyte numbers (Faddy et al., 1992), increased oocyte aneuploidy (te Velde and Pearson, 2002) and a progressive loss of ovarian follicles (Picton, 1998). Once oocytes have been lost from the ovarian reserve there is little or no renewal and, according to present dogma, the ensuing infertility is irreversible (Gosden, 2004). In 2004 interest was rekindled in neo-oogenesis following experiments in mice (Johnson et al., 2004; Johnson, 2005) and the debate continues (Tilly and Johnson, 2007; Begum et al., 2008; Bukovsky et al., 2009; Gougeon, 2010). Knowledge of the ovarian follicle reserve in the elephant may form the basis for investigations on the cause of early reproductive failure (Brown et al., 2004), reproductive senescence (Freeman et al., 2009) and the effect of contraceptives on the follicle pool (Perdok et al., 2007). 
Primordial follicles have been described as the most abundant follicle in the ovary and are commonly referred to as the building blocks of the ovarian reserve (Picton, 2001), supplying the female with oocytes throughout reproductive life. Studies in rats (Hirshfield, 1989; Oktay, 1995), cattle (Wandji et al., 1996; Braw-Tal and Yossefi, 1997), humans (Picton, 2001) and other mammals (Fortune et al., 2000) have shown that the transition from flattened pre-granulosa cells to cuboidal granulosa cells and the accompanying rounding-up of the nuclei signals that the follicle has left the ovarian reserve and is irreversibly committed to growth that may end in ovulation of or atresia. The resting pool of follicles, however, may have pre-granulosa cells that range from flat to cuboidal in shape (Lintern-Moore et al., 1974; Gougeon and Chainy, 1987; Hirshfield, 1992; Faddy and Gosden, 1995; Van Wezel and Rodgers, 1996; Meredith et al., 2000; Moss, 2001; de Bruin et al., 2002; Sawyer et al., 2002; Rodgers and Irving-Rodgers, 2009)). The biological consequences of the differences in somatic cell morphology between species is unclear and very little is known about the follicle population dynamics in long-lifespan species such as elephants. Hence, the four aims of the current study were; i) to compare the dimensions of early preantral follicles at different stages of development; ii) to compare the numbers of early pre-antral follicles at different stages of development; iii) to determine the relative abundance of early pre-antral follicles at different stages of development and; iv) to determine the type of early preantral follicle constituting the follicular reserve in subadult and adult wild African elephant. 


\section{Materials and methods}

Tissue Collection:

The ovaries of 14 African elephant cows shot by professional hunters working under annual authorization granted by The Parks and Wildlife Management Authority of Zimbabwe were used to measure and count early preantral follicles at different stages of development. Subsequently, the ovaries of another two elephant, sourced in the same way as the other 14, were used in follicle counts only. Fifteen of the 16 animals were tuskless. The ovaries were recovered within $3 \mathrm{~h}$ of death, bisected and immersed in 4\% buffered formalin (Zimvet, Harare, Zimbabwe) in a labelled $650 \mathrm{ml}$ wide-necked glass jar (Nestlé, Zimbabwe). The mandible of each animal was also collected in order to estimate its age (Laws, 1966; Jachmann, 1988).

Tissue analysis:

The fixed ovaries were weighed whole to the nearest $0.1 \mathrm{~g}$ using a Mettler AJ 100 scale, and again after any large corpora lutea (Fig. 1a) were removed by careful dissection. Four "sets" of sections, equally spaced across the ovarian surface, were cut from each pair of ovaries (see Fig. 1b). Each set consisted of 100 serial $4 \mu \mathrm{m}$ sections extending from the mesovarial margin to the free margin of the ovary and perpendicular to the tunica albuginea. Every 5th section was mounted on a glass slide (Marienfeld) and stained with haematoxylin and eosin (Sigma-Aldrich) before being examined using an Olympus BX41 microscope (Wirsam Scientific, Johannesburg, RSA). 

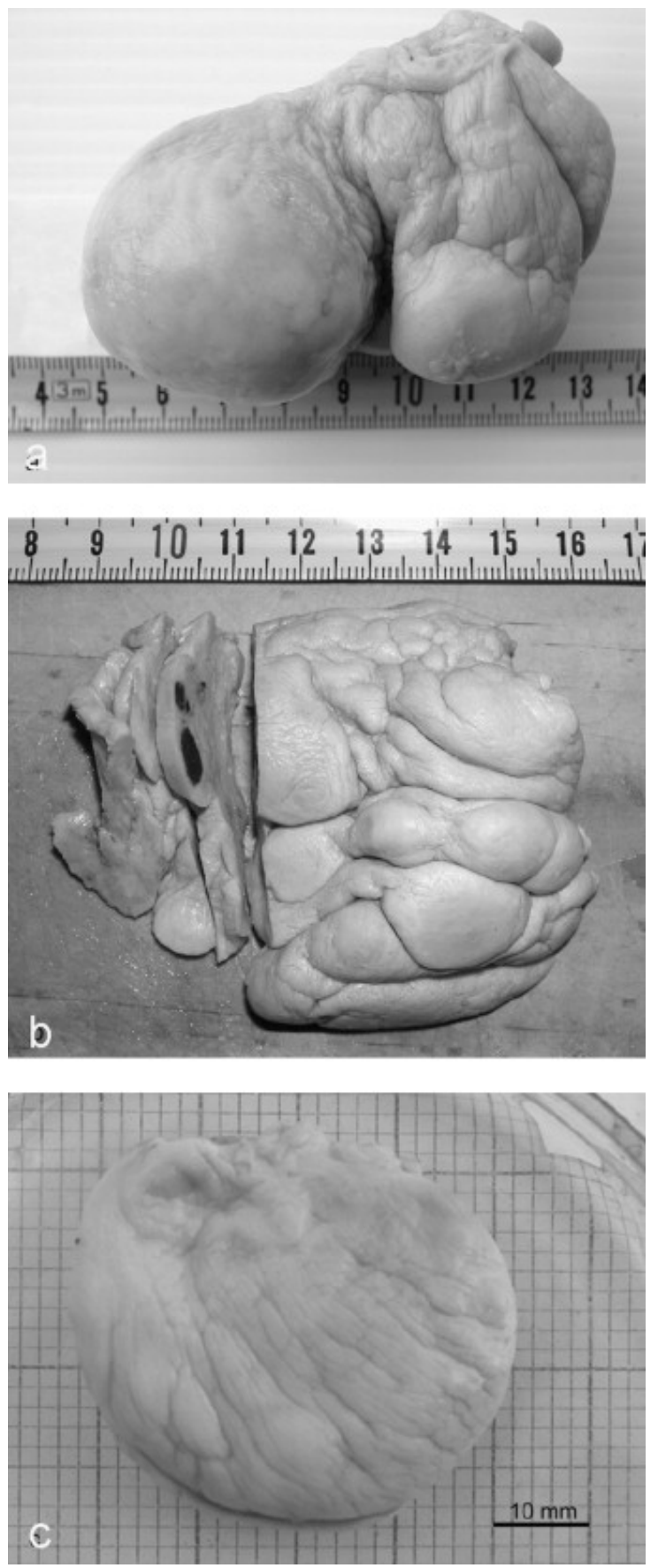

Fig. 1. Examples of elephant ovaries (a) from a pregnant elephant showing the large corpora lutea that develop during pregnancy, (b) from a non-pregnant elephant showing a cut segment revealing two corpora rubra, and (c) from a pre-pubertal elephant demonstrating the smooth and regular ovarian surface. 

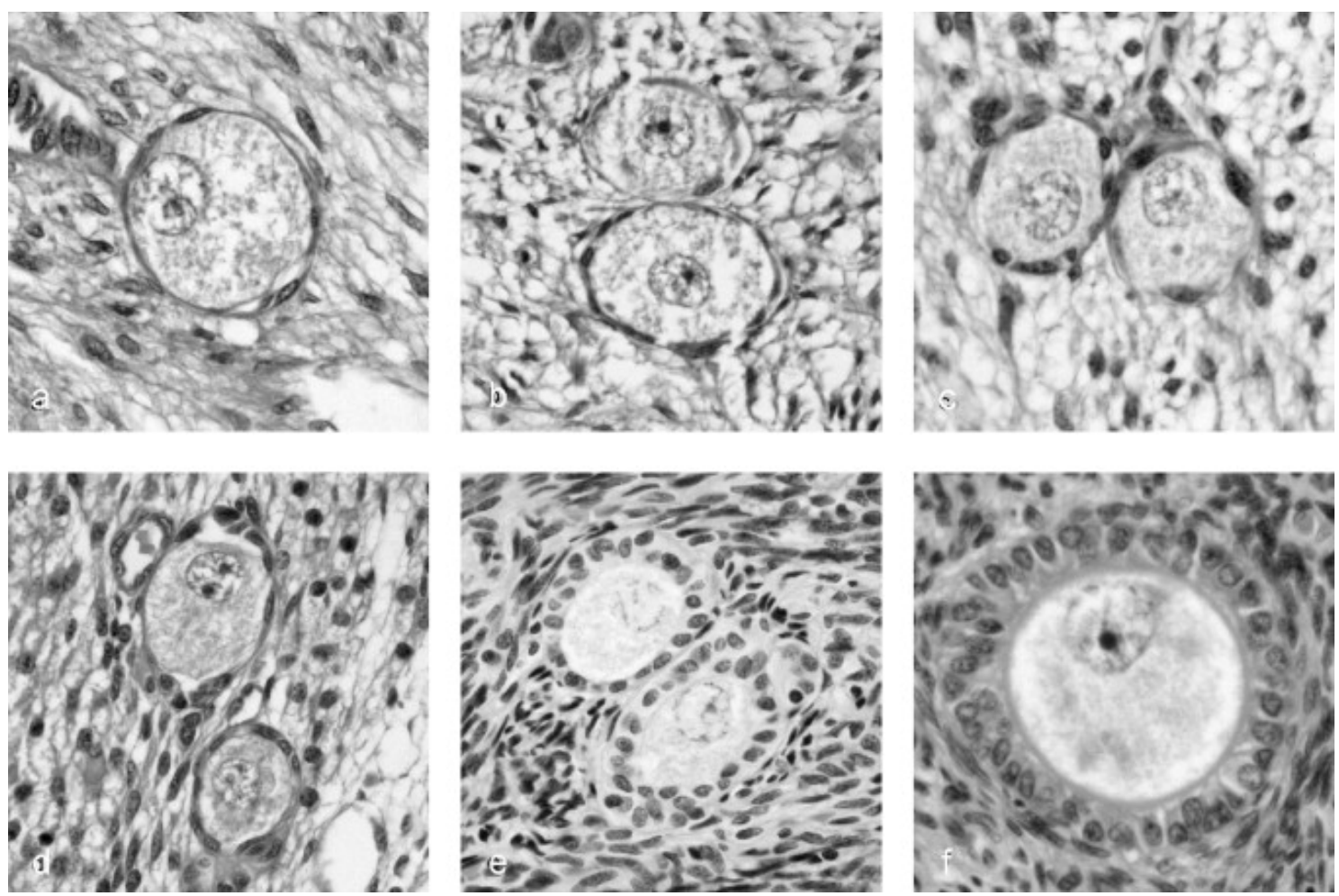

Fig. 2. Cross-sections through early antral follicles (a) primordial follicle surrounded by squamous pre-granulosa cells and bounded by a basement membrane, (b-d) early primary follicles showing the variation in follicle size and also the number and shape of pregranulosa cells, (e) true primary follicles surrounded by cuboidal pre-granulosa cells, and (f) primary follicle in transition to a secondary follicle. Magnification 400x.

The early preantral follicles were classified as; i) primordial (oocyte surrounded by a single layer of squamous pre-granulosa cells: Fig. 2a); ii) early primary (oocyte surrounded by a single layer of pre-granulosa cells of which at least one was cuboidal: Fig. 2,b,c,d); or iii) true primary, (when the oocyte was surrounded by a single layer of pre-granulosa cells of which were all cuboidal: Fig. 2e) (Oktay, 1995). The numbers of follicles in each category were counted in each stained tissue section: to avoid double counting only those follicles in which the oocyte displayed a clear nucleus were counted. From these counts the number of each type of early preantral follicle was estimated in the total population according to the method of Gougeon and Chainy (1987), and with a correction factor described by Abercrombie (1946) (Gosden and Telfer, 1987). 
Coincident with follicle counting, a range of measurements were made using a microscope fitted with an ocular micrometer. These included : i) follicle diameter, which was calculated as the average of the maximum diameter and the largest perpendicular diameter thereto (Wandji et al., 1997); ii) oocyte diameter (measured as above) and, iii) nuclear diameter (only one dimension was measured, because all nuclei appeared round in cross-section: Fig 3). The number of pre-granulosa cells surrounding the cross-section of the follicle being studied was also counted. Approximately 100 early preantral follicles were measured per animal. Sections from an animal on which follicle measurements were made were selected randomly. On each selected section all the follicles showing an approximately equatorial slice

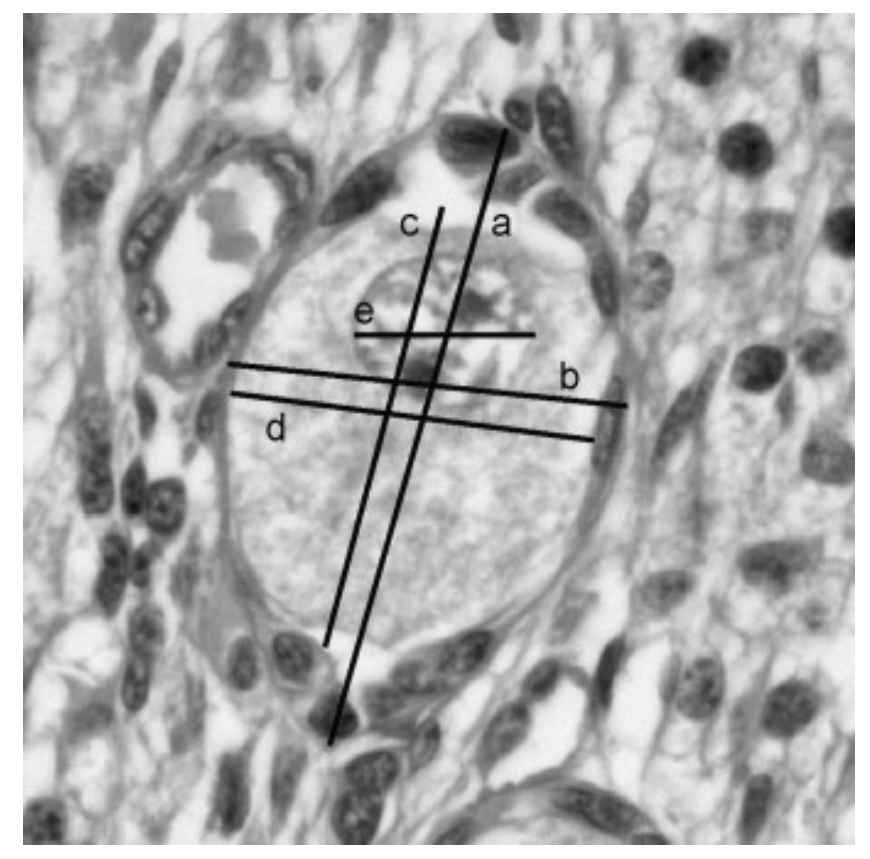

Fig. 3. Method of measuring early antral follicles: (a) maximum follicle diameter and (b) largest perpendicular diameter; (c) maximum oocyte diameter and (d) largest perpendicular diameter; (e) nuclear diameter.

through the nucleus, often denoted by the presence of the oocyte nucleoli, were measured. 
Statistical analysis:

Wilcoxon's signed rank test was used to compare i) the numbers of primordial and true primary follicles; and, ii) the numbers of true primary and early primary follicles. Wilcoxon's rank-sum test was used to compare the ages of elephant with the presence of corpora lutea and the numbers of early primary follicles in elephant with corpora lutea versus those without. The same statistical test was used to compare the numbers of early primary follicles in the 7 elephant that were $\geq 19$ years of age with that in the 6 elephant aged $\geq 25$ years. Comparisons of primordial follicles, early primary follicles and true primary follicles with respect to their dimensions and the number of pre-granulosa cells surrounding them were made (Kruskal-Wallis test). If the medians differed, Wilcoxon's rank-sum test was used to compare primordial follicles to early primary follicles and early primary follicles to true primary follicles. The skewness and kurtosis test was used to determine whether variables were normally distributed or not $(P<0.05)$. Variability is indicated as mean \pm standard deviation for normally distributed variables and as median ( $25 \%$ percentile to $75 \%$ percentile). All statistical analyses were done using STATA 11 (StataCorp, Texas, USA).

\section{Results}

Ovarian follicle dynamics was quantified in 16 elephants. In all the animals the primordial follicle population constituted $<2 \%$ of the total number of small follicles counted, whereas $75.8 \% \pm 11.8 \%$ were early primary follicles and $23.8 \% \pm 11.8 \%$ were true primary follicles. In each elephant the number of primordial follicles was the lowest, the number of early primary follicles the highest and the number of true 
primary follicles intermediate (Table 1). Overall, this ranking was highly significant ( $P<0.001$, Table 2$)$.

Table 1. The number of early preantral follicles in the ovaries of each of 16 African elephant compared to age in years and the number of ovaries containing one or more large corpora lutea $(\mathrm{CL})$.

\begin{tabular}{|c|c|c|c|c|c|}
\hline \multirow{2}{*}{ Elephant } & \multirow{2}{*}{ Age (years) } & \multirow{2}{*}{$\begin{array}{l}\text { Ovaries with } \\
\text { CL }\end{array}$} & \multicolumn{3}{|c|}{ Type of early preantral follicle } \\
\hline & & & Primordial & $\begin{array}{l}\text { Early } \\
\text { primary }\end{array}$ & $\begin{array}{l}\text { True } \\
\text { primary }\end{array}$ \\
\hline 26 & 17 & 0 & 0 & 57,488 & 2498 \\
\hline 3 & 16 & 0 & 254 & 30,137 & 11,527 \\
\hline 27 & 9 & 0 & 0 & 26,421 & 811 \\
\hline 8 & 20 & 1 & 47 & 25,320 & 6952 \\
\hline 17 & 32 & 0 & 103 & 18,615 & 4250 \\
\hline 1 & 18 & 0 & 292 & 17,900 & 4174 \\
\hline 2 & 13 & 0 & 72 & 16,623 & 13,671 \\
\hline 4 & 25 & 0 & 224 & 11,813 & 4944 \\
\hline 6 & 20 & 0 & 55 & 10,334 & 5334 \\
\hline 5 & 19 & 2 & 0 & 10,287 & 3367 \\
\hline 14 & 10 & 2 & 179 & 10,276 & 1360 \\
\hline 12 & 30 & 1 & 69 & 5920 & 4842 \\
\hline 11 & 20 & 1 & 0 & 5418 & 1603 \\
\hline 7 & 25 & 2 & 0 & 2853 & 849 \\
\hline 10 & 25 & 1 & 0 & 2196 & 775 \\
\hline 16 & 34 & 0 & 0 & 2195 & 792 \\
\hline
\end{tabular}

${ }^{a}$ All the data in the table are sorted in descending order according to the number of early primary follicles. 
Table 2. Numbers of early preantral follicles in the ovaries of 16 African elephant.

\begin{tabular}{|l|l|l|l|}
\hline \multirow{2}{*}{ Percentile } & \multicolumn{3}{|l|}{ Type of early preantral follicle } \\
\cline { 3 - 5 } & Primordial & Early primary & True primary \\
\cline { 3 - 5 } & & & \\
\hline 25th & 0 & 5669 & 11,105 \\
\hline Median & $51^{\mathrm{a}}$ & $11,074^{\mathrm{c}}$ & $3771^{\mathrm{b}}$ \\
\hline 75th & 141 & 21,968 & 5139 \\
\hline
\end{tabular}

$\mathrm{a}<\mathrm{b}<\mathrm{c}, P<0.001, n=16$ for each comparison.

The age of the elephants varied from 9 to 34 years $(20.8 \pm 7.3$ years). The 10 elephant of $\leq 20 \mathrm{yrs}$ had an average age of $16.2 \pm 4.16$ years and the 6 elephant aged $\geq 25$ years had an average age of $28.5 \pm 4.04$ years. The 10 younger elephant had 17262 (10287-26421) early primary follicles, which was significantly more than the $4387(2196-11813)$ counted in the 6 older animals $(P=0.04)$.

Seven elephant had one or more corpora lutea in their ovaries and 9 had none. The median age of elephant with corpora lutea was 20 (19-25) years, which was similar to the median age of $18(16-25)$ years in the elephant without any corpora lutea $(P=0.56)$. Yet, the 7 elephant with corpora lutea had 5920 (853-10287) early primary follicles, which was appreciably fewer than the 17900 (11813-26421) in the ovaries of the 9 elephant without corpora lutea $(P=0.04)$.

There was a progressive increase in follicle diameter and the number of pregranulosa cells surrounding the oocyte from primordial follicles to early primary follicles and on to true primary follicles $(P=0.004$ : Table 3). However, the diameter 
Table 3. Dimensions of the various types of early preantral follicles in the ovaries of 14 African elephant and the number of pre-granulosa cells surrounding them.

\begin{tabular}{|c|c|c|c|}
\hline Follicle type & Median & 75th percentile & 25th percentile \\
\hline \multicolumn{4}{|l|}{ True primordial $(n=48)$} \\
\hline Follicular diameter $(\mu \mathrm{m})$ & $40.6^{\mathrm{a}}$ & 36.3 & 43.8 \\
\hline Oocyte diameter $(\mu \mathrm{m})$ & $31.3^{d}$ & 28.1 & 33.1 \\
\hline Nucleus diameter $(\mu \mathrm{m})$ & $14.4^{f}$ & 12.5 & 15.6 \\
\hline Number of pre-granulosa cells & $6^{\text {h }}$ & 5 & 7 \\
\hline \multicolumn{4}{|l|}{ Early primary $(n=1092)$} \\
\hline Follicular diameter $(\mu \mathrm{m})$ & $43.8^{b}$ & 38.8 & 47.5 \\
\hline Oocyte diameter $(\mu \mathrm{m})$ & $30.0^{d}$ & 27.5 & 33.8 \\
\hline Nucleus diameter $(\mu \mathrm{m})$ & $15.0^{f}$ & 12.5 & 16.3 \\
\hline Number of pre-granulosa cells & $12^{\mathrm{i}}$ & 10 & 14 \\
\hline \multicolumn{4}{|l|}{ True primary $(n=324)$} \\
\hline Follicular diameter $(\mu \mathrm{m})$ & $50.0^{c}$ & 46.3 & 55.0 \\
\hline Oocyte diameter $(\mu \mathrm{m})$ & $35.0^{\mathrm{e}}$ & 32.5 & 38.9 \\
\hline Nucleus diameter $(\mu \mathrm{m})$ & $15.0^{9}$ & 12.5 & 17.5 \\
\hline Number of pre-granulosa cells & $19^{\mathrm{j}}$ & 16 & 21 \\
\hline
\end{tabular}

$\mathrm{a}<\mathrm{b}(P=0.004), \mathrm{b}<\mathrm{c}(P<0.001), \mathrm{d}<\mathrm{e}(P<0.001), \mathrm{f}<\mathrm{g}(P<0.01), \mathrm{h}<\mathrm{i}(P<0.001)$, and $\mathrm{i}<\mathrm{j}(P<0.001)$.

Table 4. Ratio of mean follicle diameter and mean oocyte diameter (D1 and D2) for each early preantral follicle class.

\begin{tabular}{|c|c|c|c|c|c|c|}
\hline \multirow{2}{*}{ Follicle stage } & \multicolumn{3}{|c|}{ Oocyte } & \multicolumn{3}{|c|}{ Follicle } \\
\hline & Ratio & D1 ( $(\mu \mathrm{m})$ & $\mathrm{D} 2(\mu \mathrm{m})$ & Ratio & $\mathrm{D} 1(\mu \mathrm{m})$ & $\mathrm{D} 2(\mu \mathrm{m})$ \\
\hline Primordial & $1.2: 1$ & 33.1 & 28.0 & $1.3: 1$ & 45.4 & 36.3 \\
\hline Early primary & $1.3: 1$ & 34.3 & 26.4 & $1.3: 1$ & 48.4 & 38.3 \\
\hline True primary & $1.3: 1$ & 40.2 & 31.0 & $1.3: 1$ & 57.1 & 44.9 \\
\hline
\end{tabular}


of the oocyte, as well as that of its nucleus, only increased when early primary follicles developed to true primary follicles $(P<0.01)$. Follicle measurements also indicated a prolate shape (Table 4).

\section{Discussion}

The current study suggests that early primary follicles and not primordial follicles constitute main follicular reserve in the African elephant because on average about $75 \%$ of small preantral follicles are early primary and less than $2 \%$ are primordial. The study also shows that reserve follicles undergo significant growth during transition from early primary follicles to true primary follicles. Further, the study suggests that young adult elephant cows, aged $28.5 \pm 4.0$ years, have fewer small preantral follicles than sub-adult cows aged $16 \pm 4.2$ years.

The established theory that only primordial follicles make up the follicle reserve in mammals is based on the premise that follicles arrest only with squamous pregranulosa cells surrounding the oocyte, and any subsequent deviation from this state indicates a commitment to growth which results in the follicles exiting from the reserve (Oktay, 1995). Three alternative theories to explain the apparent shape of the pre-granulosa cells and their relation to follicle activation can be mooted. First, the follicle pool is formed with follicles showing variously shaped pre-granulosa cells (Hirshfield, 1992; Sawyer et al., 2002). These may originate from different regions of the fetal ovary such as the mesonephros (squamous cells) or the surface epithelium (low cuboidal cells) or indeed, from neighbouring pyknotic oocytes. Second, all follicles start as primordial follicles but some show slow growth in the follicle reserve 
over many years (Fortune, 2003; van den Hurk and Zhao, 2005 ). Third, the rounding up of granulosa cell nuclei is not related to the increase in number of pregranulosa cells and is therefore not an indicator of follicle activation (Van Wezel and Rodgers, 1996). In the youngest elephant ovaries examined in the present study the number of primordial follicles counted was $<2 \%$ of the total small follicle population which suggests that one or a combination of all the above 3 theories is relevant to elephant folliculogenesis.

The molecular mechanisms that lead to follicle growth have not yet been established (Westergaard et al., 2007; Oktem and Oktay, 2008), although the morphological changes involved have been described in a number of species. The present study suggests that in African elephant primordial follicles posses few attendant pregranulosa cells, with significantly more being acquired during their transition to early primary stage. Whether this increase in the number of pre-granulosa cells is the first indication of follicle activation in the elephant remains to be confirmed. Similar kinetics have been reported in bovids (van den Hurk and Zhao, 2005 ), women (Gougeon and Chainy, 1987) and mice (Lintern-Moore and Moore, 1979).

Early preantral follicles in the African elephant are of similar dimensions to those of other large mammalian species (Gougeon and Chainy, 1987; Lundy et al., 1999). These follicles exhibit a prolate shape in the elephant (Table 4) which has also been noted in cattle (Van Wezel and Rodgers, 1996)

The present findings indicate that the total number of early preantral follicles in the African elephant reduces with increasing age (Fig. 4), which concurs with the 


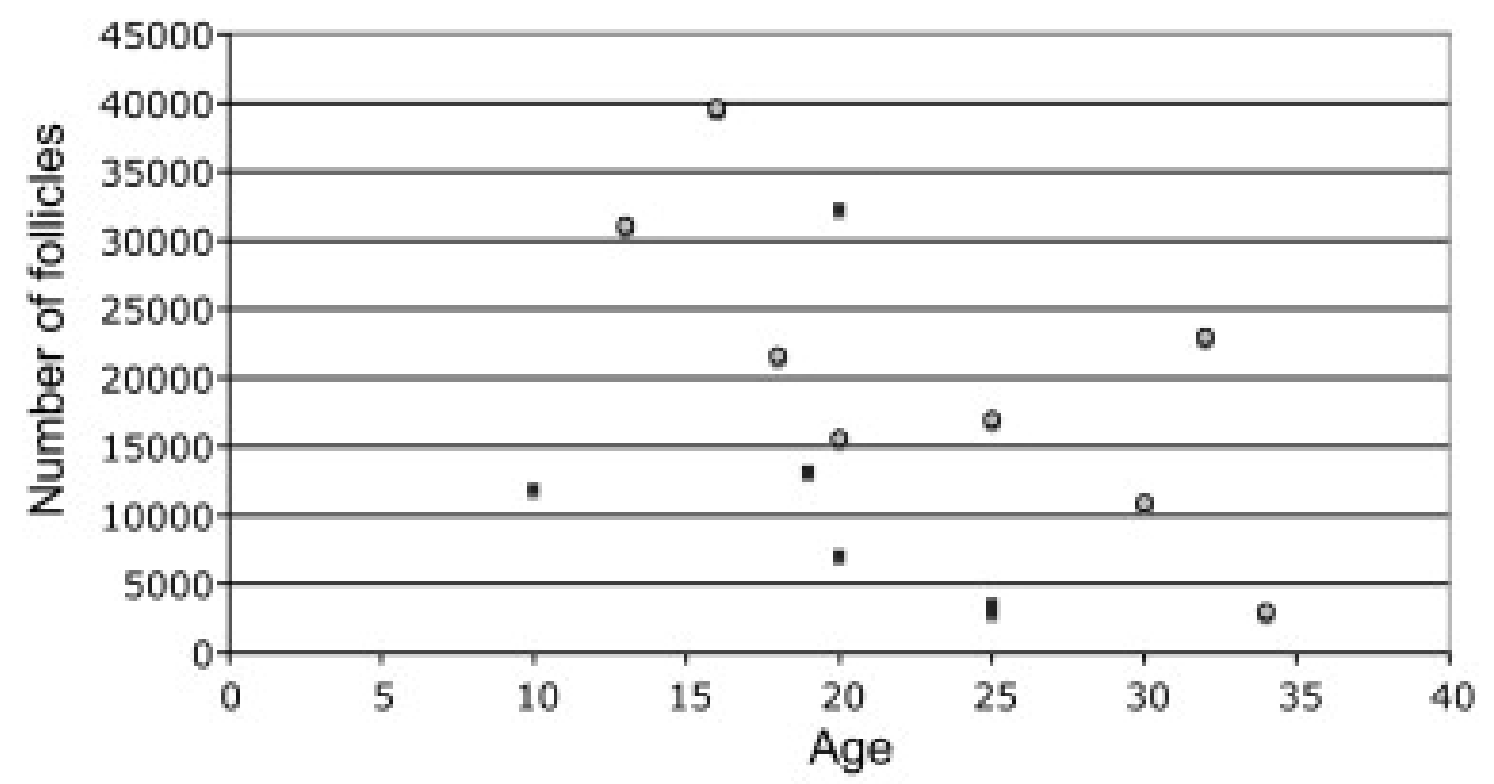

no large corpora lutea present 0 , large corpora lutea present

Fig. 4.

Number of early preantral follicles present in the ovaries of each elephant, indicating age and presence or absence of large corpora lutea.

generally held view in other mammalian species (Telfer and McLaughlin, 2007).

However, a pronounced reduction in follicle numbers was also recorded in elephant with large corpora lutea in their ovaries. This is surprising and inexplicable and requires further investigation. In each of the 16 elephant studied there were fewer primordial follicles than either early primary follicles or true primary follicles, with early primary follicles always being the most populous, suggesting that early primary follicles and not primordial follicles are the likely reservoir for the replenishment of true primary follicles. Although the method used to count follicle numbers in this study has been superseded and its possible shortcomings noted (Miller et al., 1997; Meredith et al., 1999; Charleston et al., 2007), the results have nevertheless given a ratio of small follicle classes in the elephant ovary and they have indicated that this ratio differs from those reported in other mammals. 
Some 300,000 small follicles have been recorded in the ovaries of young pubertal women ((Faddy et al., 1992), 120,000 in the ovaries of pubertal heifers (McGeady et al., 2006) and 30,000-50,000 in the ovaries of ewes, compared with the mean of only 21,253 small follicles counted in the ovaries of three 13-16 year old elephants in the present study (elephants reach puberty between 8 to 16 years of age (Laws, 1969) (Hanks, 1972). A similar comparison may be made at 30-34 years of age when 8,982 follicles were counted in 3 elephant compared to 90,000 counted in the ovaries of similarly aged women (Faddy, 2000). This suggests that, despite her extended reproductive lifespan, the African elephant retains relatively few follicles in her ovarian reserve.

The previous assumption that primordial follicles make up the vast majority of the resting follicle pool across the species is being reassessed. In healthy young women it is speculated that only a third of all early preantral follicles are at the primordial stage, most are at the early primary stage and a sizeable proportion have already reached the true primary stage (de Bruin et al., 2002). In the ovaries of bovids, $>80 \%$ of follicles are also at the early primary or true primary stages (Van Wezel and Rodgers, 1996). Likewise, Type B/C follicles (early primary) comprise $72-80 \%$ of the total population of early preantral follicles in mature rats (Meredith et al., 2000). In marked contrast, there are many species in which the majority of follicles in the ovary at any one time are primordial (Hirshfield, 1989; Oktay, 1995; Wandji et al., 1996; Braw-Tal and Yossefi, 1997; Fortune et al., 2000; Picton, 2001)

If elephants were to rely on primordial follicles as their resting pool, according to the rules of reproductive ageing ascribed to other mammalian species (Gosden, 1995), it 
follows that their ovaries would soon be devoid of potentially fertilisable oocytes, resulting in reproductive senescence relatively early in life. The recorded longevity of reproductive lifespan displayed by the female elephant (about 50 years) suggests that either she has a particularly parsimonious turnover of her follicle reserve, with far lower levels of follicle attrition than found in other mammalian species, or the somatic cells in follicles that form the reserve can vary morphologically from flat to cuboidal.

\section{Conclusions}

Findings from this study suggest that the ovarian reserve in the elephant includes both primordial and early primary follicles. It becomes important to investigate follicle dynamics in the African elephant throughout its reproductive lifespan and during fetal and postnatal life to determine the starting point of the follicle pool and to examine ovaries before their cortices become distorted by development of large structures such as the corpora lutea of pregnancy. The composition and dynamics of the early preantral follicle population can then enable an accurate description of the agerelated decline in ovarian oocytes in this species which has, in all likelihood, the longest reproductive lifespan of all land mammals.

\section{Acknowledgements}

Grateful thanks are offered to Mr Buzz Charlton for collecting elephant ovaries during professional hunts, without which this study would not have been possible. The authors also thank Professor W R (Twink) Allen for kindly reading and editing the manuscript. 


\section{References}

Abercrombie, M. (1946). Estimation of nuclear population from microtome sections. Anatomical Record 94: 236-247.

Begum, S., Papaioannou, V. E. and Gosden, R. G. (2008). The oocyte population is not renewed in transplanted or irradiated adult ovaries. Human Reproduction 23(10): 2326-2330. Braw-Tal, R. and Yossefi, S. (1997). Studies in vivo and in vitro on the initiation of follicle growth in the bovine ovary. Journal of Reproduction and Fertility 109(1): 165-171. Brown, J. L., Olson, D., Keele, M. and W, F. E. (2004). Survey of the reproductive cyclicity status of Asian and African elephants in North America. Zoo Biology 23: 309-321. Bukovsky, A., Caudie, M. R., Virant-Klun, I., Gupta, S. K., Dominguez, R., Svetlikova, M. and Xu, F. (2009). Immune physiology and oogenesis in fetal and adult humans, ovarian infertility, and totipotency of adult ovarian stem cells. Birth Defects Res C Embryo Today 87(1): 64-89.

Charleston, J. S., Hansen, K. R., Thyer, A. C., Charleston, L. B., Gougeon, A., Siebert, J. R., Soules, M. R. and Klein, N. A. (2007). Estimating human ovarian non-growing follicle number: the application of modern stereology techniques to an old problem. Human Reproduction 22(8): 2103-2110.

de Bruin, J. P., Dorland, M., Spek, E. R., Posthuma, G., van Haaften, M., Looman, C. W. N. and te Velde, E. R. (2002). Ultrastructure of the resting ovarian follicle pool in healthy young women. Biology of Reproduction 66: 1151-1160.

Delsink, A. K. (2006). Regulation of a small, discrete African elephant population through immunocontraception in the Makalali Conservancy, Limpopo, South Africa. South African Journal of Science 102(9-10): 403 - 405.

Faddy, M. J. (2000). Follicle dynamics during ovarian ageing. Molecular and Cellular Endocrinology 163(1-2): 43-48.

Faddy, M. J. and Gosden, R. G. (1995). A mathematical model of follicle dynamics in the human ovary. Human Reproduction 10(4): 770-775.

Faddy, M. J., Gosden, R. G., Gougeon, A., Richardson, S. J. and Nelson, J. F. (1992). Accelerated disappearance of ovarian follicles in mid-life: implications for forecasting menopause. Human Reproduction 7(10): 1342-1346.

Fortune, J. E. (2003). The early stages of follicular development: activation of primordial follicles and growth of preantral follicles. Animal Reproduction Science 78: 135-163. Fortune, J. E., Cushman, R. A., Wahi, C. M. and Kito, S. (2000). The primordial to primary follicle transition. Molecular and Cellular Endocrinology 25(1-2): 53-60.

Freeman, E. W., Whyte, I. J. and Brown, E. M. (2009). Reproductive evaluation of elephants culled in Kruger National Park, South Africa between 1975 and 1995. African Journal of Ecology 47: 192 - 201.

Gosden, R. (1995). Oocyte development through life. In Gametes: The Oocyte. Yovich, G. (Ed.): Cambridge Reviews in Human Reproduction.

Gosden, R. G. (2004). Germline stem cells in the postnatal ovary: is the ovary more like a testis? Human Reproduction Update 10(3): 193-195.

Gosden, R. G. and Telfer, E. (1987). Numbers of follicles and oocytes in mammalian ovaries and their allometric relationships. Journal of Zoology, London 211(1): 169-175.

Gougeon, A. (2010). Is neo-oogenesis in the adult ovary, a realistic paradigm? Gynaecology, Obstetrics and Fertility 38(6): 398-401.

Gougeon, A. and Chainy, G. B. N. (1987). Morphometric studies of small follicles in ovaries of women at different ages. Journal of Reproduction and Fertility 81: 433 - 442.

Hanks, J. (1972). Reproduction of elephant, Loxodonta africana, in the Luangwa Valley, Zambia. J Reprod Fertil 30(1): 13-26. 
Hirshfield, A. N. (1989). Granulosa cell proliferation in very small follicles of cycling rats by long-term continuous triated thymidine infusion. Biology of Reproduction 41: 309-316.

Hirshfield, A. N. (1992). Heterogeneity of cell populations that contribute to the formation of primordial follicles in rats. Biology of Reproduction 47: 466-472.

Jachmann, H. (1988). Estimating age in African elephants: a revision of Laws' molar evaluation technique. African Journal of Ecology 26: 51 - 56.

Johnson, J. (2005). Oocyte generation in adult mammalian ovaries by putative germ cells in bone marrow and peripheral blood. Cell 122: 303-315.

Johnson, J., Canning, J., Kaneko, T., Pru, J. K. and Tilly, L. (2004). Germline stem cells and follicular renewal in the postnatal mammalian ovary. Nature 428: 145-150.

Laws, R. M. (1966). Age criteria for the African elephant. East African Wildlife Journal 4: 137.

Laws, R. M. (1969). Aspects of reproduction in the African Elephant, Loxodonta Africana. Journal of Reproduction and Fertility Supplement 6: 193-217.

Lintern-Moore, S. and Moore, G. P. M. (1979). The initiation of follicle and oocyte growth in the mouse ovary. Biology of Reproduction 20: 773-778.

Lintern-Moore, S., Peters, H. and Moore, G. P. M. (1974). Follicular development in the infant ovary. Journal of Reproduction and Fertility 39: 53-64.

Lundy, T., Smith, P., O’Connell, A., Hudson, N. L. and McNatty, K. P. (1999). Populations

of granulosa cells in small follicles of the sheep ovary. Journal of Reproduction and Fertility 115: 251-262.

McGeady, T. A., Quinn, P. J., FitzPatrick, E. S. and Ryan, M. T. (2006). Male and Female Reproductive Systems. In Veterinary Embryology. Blackwell Publishing.

Meredith, S., Dudenhoeffer, G. and Jackson, K. (1999). Single-section counting error when distinguishing between primordial and early primary follicles in sections of rat ovary of different thickness. Journal of Reproduction and Fertility 117: 339-343.

Meredith, S., Dudenhoeffer, G. and Jackson, K. (2000). Classification of small type B/C follicles as primordial follicles in mature rats. Journal of Reproduction and Fertility 119: 4348.

Miller, P. B., Charleston, J. S., Battaglia, D. E., Klein, N. A. and Soules, M. R. (1997). An accurate, simple Method for unbiased determination of primordial follicle number in the primate ovary. Biology of Reproduction 56: 909-915.

Moss, C. (2001). The demography of an African elephant (Loxodonta africana) population in Amboseli, Kenya. Journal of Zoology London 255: 145 - 156.

Oktay, K. (1995). Proliferating cell nuclear antigen marks the initiation of follicular growth in the rat. Biology of Reproduction 53: 295-301.

Oktem, O. and Oktay, K. (2008). The ovary: anatomy and function throughout human life. Annals of the New York Academy of Science 1127: 1-9.

Perdok, A. A., de Boer, W. F. and Stout, T. A. F. (2007). Prospects for managing African elephant population growth by immunocontraception: a review. Pachyderm 42(JanuaryJune): 97 - 107.

Perry, J. S. (1953). The reproduction of the African elephant, Loxodonta africana.

Philosophical Transactions of the Royal Society of London B Biological Science 237(643):

93-149.

Picton, H. (1998). The molecular basis of oocyte growth and development.

Picton, H. M. (2001). Activation of follicle development: the primordial follicle.

Theriogenology 55(6): 1193-1210.

Proctor, C. M., Freeman, E. W. and Brown, J. L. (2010). Results of a second survey to assess the reproductive status of female Asian and African elephants in North America. Zoo Biology 29: 127-139. 
Rodgers, R. J. and Irving-Rodgers, H. F. (2009). The morphological classification of bovine ovarian follicles. Reproduction.

Sawyer, H. R., Smith, P., Heath, D. A., Juengel, J. L., Wakefield, S. J. and McNatty, K. P. (2002). Formation of ovarian follicles during fetal development in sheep. Biology of Reproduction 66: 1134-1150.

te Velde, E. R. and Pearson, P. L. (2002). The variability of female reproductive ageing. Human Reproduction Update 8(2): 141-154.

Telfer, E. E. and McLaughlin, M. (2007). Natural history of the mammalian oocyte. Reprod Biomed Online 15(3): 288-295.

Tilly, J. L. and Johnson, J. (2007). Recent arguments against germ cell renewal in the adult human ovary: is an absence of marker gene expression really acceptable evidence of an absence of oogenesis? Cell Cycle 6(8): 879-883.

van den Hurk, R. and Zhao, J. (2005 ). Formation of mammalian oocytes and their growth, differentiation and maturation within ovarian follicles. Theriogeneology 63: 1717-1751.

Van Wezel, I. L. and Rodgers, R. J. (1996). Morphological characterization of bovine primordial follicles and their environment in Vivo. Biology of Reproduction 55: 1003-1011. Wandji, S. A., Srsen, V., Eppig, J. J. and Fortune, J. E. (1996). Initiation In Vitro of growth of bovine primordial follicles. Biology of Reproduction 55: 942-948.

Wandji, S. A., Srsen, V., Nathanielsz, P. W., Eppig, J. J. and Fortune, J. E. (1997). Initiation of growth of baboon primordial follicles in vitro. Human Reproduction 12(9): 1993-2001.

Westergaard, C. G., Byskov, A. G. and Andersen, C. Y. (2007). Morphometric characteristics of the primordial to primary follicle transition in the human ovary in relation to age. Human Reproduction 22(8): 2225-22231.

Whyte, I. J. (2004). Ecological basis of the new elephant management policy for Kruger national Park and expected outcomes. Pachyderm 36: 99-108. 